\title{
Ovarian Seromucinous Adenofibroma
}

National Cancer Institute

\section{Source}

National Cancer Institute. Ovarian Seromucinous Adenofibroma. NCI Thesaurus. Code C126311.

A non-metastasizing mixed epithelial neoplasm that arises from the ovary. It is characterized by the presence of more than one epithelial cell type, most often serous and endocervical-type mucinous and prominent fibrous stroma.. 